\title{
Surgery versus medical follow-up in patients with asymptomatic primary hyperparathyroidism: a decision analysis
}

\author{
Karine Sejean $^{1}$, Sophie Calmus ${ }^{1}$, Isabelle Durand-Zaleski ${ }^{7}$, Philippe Bonnichon ${ }^{2}$, Pierre Thomopoulos ${ }^{3}$, \\ Catherine Cormier ${ }^{4}$, Paul Legmann ${ }^{5}$, Bruno Richard ${ }^{6}$, Xavier Y Bertagna ${ }^{3}$ and Gwenaelle M Vidal-Trecan ${ }^{1}$ \\ Université Paris Descartes, Faculté de Médecine, Services de ${ }^{1}$ Santé publique, ${ }^{2}$ Chirurgie générale et digestive, ${ }^{3}$ d'endocrinologie et métabolisme, \\ ${ }^{4}$ Rhumatologie A, ${ }^{5}$ Radiologie A and ${ }^{6}$ Biophysique - médecine nucléaire, AP-HP, groupe hospitalier Cochin - Saint Vincent de Paul, 27 rue du faubourg \\ Saint Jacques, 75014 Paris, France and ${ }^{7}$ HAS et Service de Santé publique, hôpital Henri Mondor, AP-HP, Université Paris 12, Paris, France \\ (Correspondence should be addressed to G Vidal-Trécan; Email: gwenaelle.vidal-trecan@univ-paris5.fr)
}

\begin{abstract}
Objectives: To examine the cost-effectiveness of strategies for management of primary asymptomatic hyperparathyroidism: surgical strategies and medical follow-up versus surgery.

Design: We used a Markov state-transition decision-analytic model for an hypothetical cohort of 55year-old women to compare with a lifetime horizon costs and effectiveness of bilateral neck exploration (BNE), unilateral neck exploration (UNE), video-assisted parathyroidectomy (VAP) and lifelong medical follow-up shifting for either BNE or UNE in case of disease progression.

Methods: Data on localization tests, complications and treatment efficacies were derived from a systematic review of the literature. Outcomes were expressed as quality-adjusted life years (QALY). Costs $(€ 2002)$ discounted at 3\% yearly were estimated from the health care system perspective.

Results: In the base-case analysis, VAP strategy (VAPS) was the most effective and BNE strategy (BNES) was the least costly. UNE strategy (UNES) had an incremental cost-effectiveness ratio of $€ 2688$ /QALY versus BNES and VAPS of $€ 17$ 250/QALY in comparison with UNES. Surgical management was more effective than medical follow-up with acceptable incremental cost-effectiveness ratios. VAPS became less effective than UNES over 71 years. Differences between UNES and VAPS were sensitive to success and complication rates, quality-of-life weights and procedural costs. Medical follow-up strategies became the most effective if quality-of-life weight for this condition was higher than 0.99 .

Conclusions: Surgery is more effective than medical follow-up at a reasonable cost and can be preferred except in patients choosing medical follow-up. Minimally invasive surgery is cost-effective compared to the traditional surgical approach.
\end{abstract}

European Journal of Endocrinology 153 915-927

\section{Introduction}

Primary hyperparathyroidism is a rather common disorder. Its prevalence and incidence have been estimated to be $0.1-0.5 \%$ and $0.03 \%$, respectively ( 1 , $2)$. Parathyroidectomy is presently the only definitive treatment for primary hyperparathyroidism (3). Some medical therapies have been proposed but none have yet been proved to be both effective and safe in the long term (3). As $49 \%$ of patients are asymptomatic, North American guidelines on the management of asymptomatic primary hyperparathyroidism limit indications to surgery to patients with risk factors for complications $(3,4)$. Patients with a mildly elevated calcemia, no previous episodes of lifethreatening hypercalcemia and normal renal and bone status, can be assigned to medical monitoring, shifting to parathyroidectomy only in the case of progression of the disease.

Three main surgical approaches are currently available: traditional bilateral neck exploration (BNE) and two minimally invasive approaches, unilateral neck exploration (UNE) and video-assisted endoscopic parathyroidectomy (VAP) (5). Proponents of BNE argue that it is a safe procedure with the highest cure rate and low morbidity when performed by experienced surgeons because $12-15 \%$ of patients with primary hyperparathyroidism may have diffuse hyperplasia and $2 \%$ have double or triple adenoma. Both minimally invasive procedures are indicated if preoperative localization studies and intra-operative parathyroid hormone (PTH) monitoring prove a single adenoma. Proponents of minimally invasive surgery argue that these procedures decrease surgical costs and morbidity 
while improving cosmesis. To our knowledge, the outcomes of these surgical approaches had never been evaluated together in randomized clinical trials. UNE has been compared to BNE $(6-15)$ and might be safer and more effective, only one small randomized study has compared the outcomes of VAP with those of BNE (16). Moreover, only three studies (17-19) have explored the efficacy of medical follow-up compared to surgery. Among them, only one (17) concluded that surgery was more effective in asymptomatic patients.

Short-term economic evaluations of various surgical procedures $(6,12,20-33)$ have been conducted although are seldom related to outcomes. A recent cost analysis (24) concluded that the use of any preoperative localizing strategy before an initial operation, especially when leading to UNE, is cost-beneficial compared to nondirected BNE. Cost-effectiveness studies (6, $12,25-33$ ) of UNE versus BNE leading to controversial conclusions did not meet the methodological standards (34-36). Furthermore, the cost-effectiveness of medical monitoring compared to surgery has not yet been established $(1,37)$.

Thus to our knowledge the effectiveness and costs of the strategies for asymptomatic primary hyperparathyroidism have not been compared until now. Our objective was to answer the following questions for patients with sporadic primary hyperparathyroidism excluding those with multiple endocrine neoplasia or parathyroid cancer. Which is the most effective surgical approach in patients eligible for surgery? Is long-term medical follow-up an effective option compared with immediate surgery in patients not eligible for surgery? Are minimally invasive surgical approaches or longterm follow-up cost-effective options?

The method chosen was a decision-analytic model with base-case analysis and variations of every parameter in sensitivity analyses.

\section{Methods}

\section{Literature review}

We reviewed both the English and French language medical literature from 1970 to 2004, using a structured Medline search supplemented by manual searches of bibliographies of selected articles. Studies were excluded if the patient series was less than 30, if they did not report separate results for primary hyperparathyroidism and other hyperparathyroidisms, for primary surgery and reoperation, if results for patients with multiple endocrine neoplasia or parathyroid cancer could not be excluded, or if localization studies had been performed in the series reporting results of BNE. If the same patient series was published more than once, only data from the latest publication were included. Among studies reporting results of parathyroid localization the studies selected were those reporting quantitative data allowing categorization of each patient as a true or false positive. When possible a summary analysis was performed and exact 95\% confidence intervals calculated (38).

\section{Efficacy and complications of the surgical procedures}

Apart from death never reported after UNE or VAP, potential complications (Table 1) were identical for each of the surgical procedures examined $(10,11$, $13,23,27,29,39-79)$. Surgical failure was ascertained on persistent hypercalcemia immediately after surgery. Short-term complications $(<6$ months $)$ included hematoma requiring evacuation, transient vocal cord palsies and hypocalcemia. Long-term complications (>6 months) were permanent dysphonia or hypoparathyroidism $(10,13,27,40-44,47,52,53$, 55-58, 61, 63, 67, 69). Hyperparathyroidism may recur $(41,47,55,57,71,73,75)$ but recurrence rates after VAP are unknown $(16,80-84)$.

\section{Localization studies}

For each localization study, positive predictive value and proportion of positive results are summarized in Table 2. Results of localization studies were classified as true positive if a single adenoma was detected in the neck both by imaging and by an initial operation or for reoperation if all glands enlarged (adenomas or hyperplasia) detected during the intervention were found by preoperative localization.

\section{Medical follow-up}

During a 10-year medical follow-up $(85,86), 24.5 \%$ of asymptomatic patients underwent surgery by the following guidelines: increase in calcemia $(7.55 \%)$, decrease in creatinine clearance $(3.77 \%)$ or decrease in bone mineral density $(3.77 \%)(87)$.

\section{Case definition}

Sporadic primary hyperparathyroidism (cancer excluded) was defined by hypercalcemia in the presence of inappropriately normal or elevated levels of PTH $(88,89)$. Seventy-five per cent of patients are women with an average age at diagnosis of 55 years (90). Our base-case was therefore a 55-year-old woman with asymptomatic hyperparathyroidism; cases were simulated in which she was eligible for surgery without previous neck surgery and also in which she was not eligible for surgery (3). 
Table 1 Rates, probabilities and utilities used in the baseline and sensitivity analyses for cost-effectiveness analysis of primary hyperparathyroidism.

\begin{tabular}{|c|c|c|c|c|}
\hline \multirow[b]{2}{*}{ Health state } & \multirow[b]{2}{*}{ Rates and probabilities } & \multirow{2}{*}{$\begin{array}{l}95 \% \text { Cls or extreme } \\
\text { values }^{\star}\end{array}$} & \multicolumn{2}{|c|}{ QOL adjustment factor } \\
\hline & & & Short term† & Long term $\ddagger$ \\
\hline \multicolumn{5}{|l|}{ BNE } \\
\hline \multicolumn{5}{|l|}{ First operation } \\
\hline \multicolumn{5}{|l|}{ Short-term events } \\
\hline Surgery & & & 3.88 & 0.9924 \\
\hline Death & $0.21 \%(40,42,43,46,47,49,52)$ & $0.01-0.48 \%$ & & \\
\hline Hematoma & $0.37 \%(40,43,56,57)$ & $0.02-2.38 \%$ & 2 & \\
\hline Transient dysphonia & $\begin{array}{c}1.87 \%(23,27,40,42-44,46,48 \\
50,52-54,56,57,59)\end{array}$ & $1.26-2.75 \%$ & 1.54 & \\
\hline Transient hypocalcemia & $\begin{array}{l}9.98 \%(23,40,42-44,46-51 \\
53-57,59)\end{array}$ & $8.82-11.27 \%$ & & \\
\hline Persistent hyperparathyroidism & $5.28 \%(23,27,29,39-49,51-60)$ & $4.49-6.20 \%$ & & 0.9047 \\
\hline \multicolumn{5}{|l|}{ Long-term events } \\
\hline Permanent dysphonia & $0.00 \%(43,44,47,52,58)$ & $0.00-0.48 \%$ & & 0.8913 \\
\hline Permanent hypoparathyroidism & $1.75 \%(27,42-44,52,53,55-57)$ & $1.12-2.71 \%$ & & 0.8941 \\
\hline Recurrent hyperparathyroidism & $0.06 \% /$ year $(41,47,55)$ & $0.02-0.16 \%$ & & \\
\hline Scar & $100 \%$ & & & 0.9924 \\
\hline \multicolumn{5}{|l|}{ Reoperation } \\
\hline \multicolumn{5}{|l|}{ Short-term events } \\
\hline Surgery & & & 11.10 & 0.9924 \\
\hline Death & $0.29 \%(71-76)$ & $0.02-1.87 \%$ & & \\
\hline Hematoma & $3.92 \%(109)$ & $0.68-14.59 \%$ & 2 & \\
\hline Transient dysphonia & $3.49 \%(71-76)$ & $1.90-6.18 \%$ & 1.54 & \\
\hline Transient hypocalcemia & $10.40 \%(73-76)$ & $7.03-15.03 \%$ & & \\
\hline Persistent hyperparathyroidism & $10.17 \%(71-76)$ & $7.28-13.98 \%$ & & 0.9047 \\
\hline \multicolumn{5}{|l|}{ Long-term events } \\
\hline Permanent dysphonia & $0.47 \%(71,74,75)$ & $0.02-2.98 \%$ & & 0.8913 \\
\hline Permanent hypoparathyroidism & $5.61 \%(71,74,75)$ & $3.06-9.83 \%$ & & 0.8941 \\
\hline Recurrent hyperparathyroidism & $0.70 \% /$ year $(71,73,75)$ & $0.31-1.51 \%$ & & \\
\hline Scar & $100 \%$ & & & 0.9924 \\
\hline \multicolumn{5}{|l|}{ UNE } \\
\hline \multicolumn{5}{|l|}{ Short-term events } \\
\hline Surgery & & & 3.36 & 0.9979 \\
\hline Hematoma & $\begin{array}{l}0.59 \%(10,57,62-64,66 \\
\quad 68,70)\end{array}$ & $0.23-1.50 \%$ & 2 & \\
\hline Transient dysphonia & $1.09 \%(10,11,57,62-64,66-70)$ & $0.59-2.00 \%$ & 1.54 & \\
\hline Transient hypocalcemia & $\begin{array}{l}6.28 \%(10,11,13,57,61 \\
\quad 63-67,69)\end{array}$ & $4.66-8.37 \%$ & & \\
\hline Persistent hyperparathyroidism $\S$ & & & & 0.9047 \\
\hline Sestamibi scintigraphy & $6.43 \%(60,61,63-65,69)$ & $4.17-9.72 \%$ & & \\
\hline Ultrasonography & $5.62 \%(10,13,68,98)$ & $3.84-8.12 \%$ & & \\
\hline $\begin{array}{l}\text { Ultrasonography and } \\
\text { sestamibi scintigraphy }\end{array}$ & $3.50 \%(11,57,70)$ & $1.54-7.37 \%$ & & \\
\hline \multicolumn{5}{|l|}{ Long-term events } \\
\hline Permanent dysphonia & $0.00 \%(63)$ & $0.00-6.76 \%$ & & 0.8913 \\
\hline Permanent hypoparathyroidism & $0.00 \%(10,63,67)$ & $0.00-2.42 \%$ & & 0.8941 \\
\hline Recurrent hyperparathyroidism & $0.34 \% /$ year (57) & $0.06-1.36 \%$ & & \\
\hline Scar & $100 \%$ & & & 0.9979 \\
\hline \multicolumn{5}{|l|}{ VAP } \\
\hline \multicolumn{5}{|l|}{ Short-term events } \\
\hline Surgery & & & 7.44 & 0.9988 \\
\hline Anesthesia-related death & $0.0054 \%(100)$ & & & \\
\hline Conversion into bilateral neck exploration & $11.75 \%(80-82,84)$ & $9.68-14.26 \%$ & & \\
\hline Hematoma & $0.38 \%(80-82,84)$ & $0.13-1.63 \%$ & 2 & \\
\hline Transient dysphonia & $0.64 \%(80-82,84)$ & $0.24-1.57 \%$ & 1.54 & \\
\hline Transient hypocalcemia & $1.66 \%(80-82,84)$ & $0.93-2.90 \%$ & & \\
\hline Persistent hyperparathyroidism§ & $1.40 \%(80-82,84)$ & $0.74-2.58 \%$ & & 0.9047 \\
\hline \multicolumn{5}{|l|}{ Long-term events } \\
\hline Permanent dysphonia & $0.38 \%(80-82,84)$ & $0.10-1.21 \%$ & & 0.8913 \\
\hline Permanent hypoparathyroidism & $0.00 \%(80-82,84)$ & $0.00-0.61 \%$ & & 0.8941 \\
\hline Recurrent hyperparathyroidism & $0.34 \% /$ year & $0.06-1.36 \%$ & & \\
\hline Scar & $100 \%$ & & & 0.9988 \\
\hline
\end{tabular}


Table 1. Continued

\begin{tabular}{|c|c|c|c|c|}
\hline \multirow[b]{2}{*}{ Health state } & \multirow[b]{2}{*}{ Rates and probabilities } & \multirow[b]{2}{*}{$\begin{array}{c}95 \% \\
\text { values }^{\star}\end{array}$} & \multicolumn{2}{|c|}{ QOL adjustment factor } \\
\hline & & & Short term† & Long term $\ddagger$ \\
\hline \multicolumn{5}{|l|}{ Cervicosternotomy } \\
\hline \multicolumn{5}{|l|}{ Short-term events } \\
\hline Surgery & & & 12.37 & 0.9827 \\
\hline Death & $1.89 \%(77-79)$ & $0.33-7.32 \%$ & & \\
\hline Hematoma & $2.74 \%(78,79)$ & $0.48-10.44 \%$ & 2 & \\
\hline Transient dysphonia & $6.85 \%(78,79)$ & $2.55-15.93 \%$ & 1.54 & \\
\hline Transient hypocalcemia & $33.96 \%(77-79)$ & $25.22-43.88 \%$ & & \\
\hline Persistent hyperparathyroidism & $16.18 \%(77,79)$ & $8.73-25.53 \%$ & & 0.9047 \\
\hline \multicolumn{5}{|l|}{ Long-term events } \\
\hline Permanent dysphonia & $12.68 \%(77,78)$ & $6.31-23.20 \%$ & & 0.8913 \\
\hline Permanent hypoparathyroidism & $2.63 \%(78)$ & $0.14-15.43 \%$ & & 0.8941 \\
\hline Recurrent hyperparathyroidism & $0.00 \% /$ year (77) & $0.00-3.08 \%$ & & \\
\hline Scar & $100 \%$ & & & 0.9827 \\
\hline Medical follow-up & & & & 0.9047 \\
\hline Indication for surgical treatment & $0.78 \% /$ year $(85,86)$ & $0.38 \% /$ year $-2.81 \% /$ year & & \\
\hline
\end{tabular}

* $95 \%$ confidence intervals (Cls) or extreme values indicate the range of rates examined in the sensitivity analyses. When possible, exact $95 \%$ confidence intervals were estimated (38).

$\dagger$ For short-term outcomes quality-adjustment factor is expressed in days and subtracted from life expectancy.

¥For long-term outcomes quality-adjustment factor is multiplied by life expectancy.

$\S$ The risk of persistent hyperparathyroidism varies according to the localization studies performed and to other factors.

If Not yet available in the literature and assumed in the base-case to be similar to values estimated for limited neck exploration.

\section{Decision-analytic model}

We examined the cost-effectiveness of five strategies for managing patients with primary hyperparathyroidism. The following strategies were compared first: (1) surgical BNE strategy (BNES); (2) UNE strategy (UNES); (3) VAP strategy (VAPS). These strategies were compared next with (4) lifelong medical follow-up followed by either BNES (Follow-up/BNES) or (5) UNES (Followup/UNES) in the event of a change in the value of the parameters monitored leading to a surgical indication (3). We used Decision Maker (Decision Maker Software, Beta version 2002) (91, 92), a decision-analysis software package, to model these strategies as a Markov state-transition decision-analytic model $(93,94)$ and to perform base-case and sensitivity analyses. We used a 1-month cycle length and a lifetime horizon (the decision model is available upon request from $G$
M V-T). Rates and probabilities of complications used in the model for the base-case appear in Table 1.

In the BNES (Table 1), patients were hospitalized and explored under general anesthesia without any previous localization study. Short-term complications included hematoma, transient vocal-cord paralysis and death. Hematoma resulted in a reoperation with its risk of death from general anesthesia. Every patient visited a specialist 1 and 6 months after surgery and received calcium and alfacalcidol for 15 days to prevent post-surgical hypocalcemia. This treatment was extended for 6 months in patients with transient hypoparathyroidism. Patients with persistent hypercalcemia were reoperated 6 months later after ultrasonography, sestamibi scintigraphy, venous catheterization with PTH assessment, computed tomography (CT) and magnetic resonance imaging (MRI). According to the results of these localization studies, a BNE or a cervicosternotomy (Table 1)

Table 2 Positive predictive values (PPVs) and rates of positive results of localization studies performed before UNE or VAP.

\begin{tabular}{llr}
\hline Preoperative localization & PPV (95\% Cl) & Positive rates (95\% Cl) \\
\hline First operation & & \\
Sestamibi scintigraphy $(29,33,60,65,110-116)$ & $94 \%(91-96 \%)$ & $77 \%(75-79 \%))$ \\
Ultrasonography $(11,53,54,112,117)$ & $97 \%(93-99 \%)$ & $73 \%(69-76 \%)$ \\
Reoperation & $91 \%(83-96 \%)$ & $83 \%(79-87 \%)$ \\
Sestamibi scintigraphy $(109,118,119)$ & $86 \%(73-94 \%)$ & $71 \%(65-77 \%)$ \\
Ultrasonography (119) & $74 \%(60-84 \%)$ & $58 \%(53-64 \%)$ \\
Computed tomography (120-122) & $82 \%(72-90 \%)$ & $80 \%(76-84 \%)$ \\
Magnetic resonance imaging (118, 121, 122) & $91 \%(87-94 \%)$ & $78 \%(76-81 \%)$ \\
Venous catheterization with intact parathormone dosage (118, 123-128) & & \\
\hline
\end{tabular}

$\mathrm{Cl}$, confidence interval. 
was performed. Permanent dysphonia or hypoparathyroidism were assumed to occur after each of these surgical procedures only in patients who experienced transient dysphonia or hypoparathyroidism. Patients without any complication underwent a lifelong medical followup including a visit each year to the general practitioner and calcemia measurement. In case of recurrence, patients underwent reoperation (BNE or cervicosternotomy; Table 1) after ultrasonography, sestamibi scintigraphy, venous catheterization with PTH assessment, CT scanning and MRI.

In the UNES (Table 1), patients underwent in preoperative cervical ultrasonography and sestamibi scintigraphy in a day-care setting. If both were positive (localization of a single adenoma in the neck), patients underwent UNE under local anesthesia; if not, they underwent BNE. Rapid intraoperative assays of PTH confirmed the resection of a single adenoma by an adequate reduction in PTH levels (5). Surgical failure was assumed to depend on both the positive predictive values of localization studies and other factors such as the surgeon's skills. Short- and long-term complications of UNE were the same as those of BNE except for death. Post-operative monitoring was identical. Patients with persistent hypercalcemia or recurrent hyperparathyroidism were reoperated on 6 months later or when detected, respectively. They underwent BNE or cervicosternotomy (Table 1) according to the results of ultrasonography, sestamibi scintigraphy, venous catheterization with PTH assessment, CT scanning and MRI.

In the VAPS (Table 1), ultrasonography and sestamibi scintigraphy were performed in day-care settings: if both were positive, patients underwent VAP under general anesthesia; if not, they underwent BNE. PTH was measured using intraoperative assays. When VAP failed to find the adenoma, a BNE was performed immediately. Short-term complications included death related to general anesthesia. Other complications were the same as those for BNE. The rate of recurrence was assumed to be the same as after UNE.

In the medical follow-up strategies (Table 1), patients were monitored according to the guidelines and may have experienced nonspecific symptoms (3). We assumed no incremental risk of death. Either BNE or UNE was performed when patients met at least one criterion for surgery thus avoiding complications of hyperparathyroidism such as fractures or renal colic attacks.

\section{Effectiveness}

Outcomes were expressed as quality-adjusted life expectancy. Population-based mortality rates were derived from French tables of vital statistics.

\section{Quality of life (QOL)}

We adjusted life expectancy for both short-term (for example complications such as hematoma, hospitalization or recovery) and long-term (complications such as dysphonia or hypoparathyroidism, persistent hyperparathyroidism or scarring) morbidity. Mean QOL weights for each health state (short-term and long-term morbidities) identified as potentially reducing QOL (Table 1) were drawn from a survey in an opportunistic sample of 109 volunteers without the disease. Utilities of health states were elicited using the time trade-off method (95) by one trained interviewer.

\section{Costs}

Costs (Table 3) were computed from the healthcare delivery system perspective and were expressed in $€$ for the year 2002. Average total inpatient costs were derived from the cost accounting system of the Assistance Publique - Hôpitaux de Paris, a hospital network of 50 non-profit university hospitals in the Paris region. Non-healthcare costs were not considered. Hospital costs included all personnel costs, supplies, drugs and blood products, tests, housekeeping and hospital overheads. Ambulatory costs were estimated using the national reimbursement schedule provided by the Social Security, prices for drugs were derived from the French Red Book (Dictionnaire Vidal). Guidelines (3) were used to estimate the periodicity of clinic visits and tests during medical follow-up. Experts' opinions were used for recovery lengths. Costs and health benefits were discounted at 3\% yearly $(95,96)$.

\section{Sensitivity analyses}

Sensitivity analyses (one- or two-way) were performed on every variable included in the model. The extreme values of reported data or the estimated 95\% confidence intervals were used (Table 2). We varied major cost components (for example length of hospitalization and frequency of ambulatory follow-up) and QOL adjustments. All sensitivity analyses used a discount rate of $3 \%$ unless otherwise noted.

\section{Results}

\section{Base-case analysis}

In a 55-year-old woman with sporadic asymptomatic hyperparathyroidism eligible for surgery (Table 4a), the VAPS was marginally the most effective strategy, resulting in a gain of 0.004 QALY (1.46 days) compared with UNES (0.0892 QALY; 32.49 days) compared with BNES. UNES resulted in a gain of 0.0852 QALY (31.03 days) compared with BNES and its incremental cost-effectiveness ratio was $€ 2688$ /QALY. The incremental cost-effectiveness ratio of VAPS was $€ 17$ 250/QALY compared with UNES (€3341/QALY) and BNES (less than €20 000/QALY). 
Table 3 Average costs of (a) management for hyperparathyroidism and (b) complications of therapy for primary hyperparathyroidism.

\begin{tabular}{|c|c|c|c|}
\hline Therapy & $\begin{array}{l}\text { First-month cost } \\
\qquad(€)\end{array}$ & $\begin{array}{c}\text { Subsequent patient } \\
\text { cost for first year } \\
(€)\end{array}$ & $\begin{array}{l}\text { Subsequent outpatient } \\
\text { costs, following years } \\
(€)\end{array}$ \\
\hline \multicolumn{4}{|l|}{ (a) } \\
\hline \multicolumn{4}{|l|}{ BNE } \\
\hline \multicolumn{4}{|l|}{ First operation } \\
\hline Outpatient visits $\dagger$ & $69(3)$ & $46(2)$ & $20(1)$ \\
\hline Biological and hormonal measurements $\ddagger$ & 116 & 164 & 8 \\
\hline Surgery§ & 2100 & NA & NA \\
\hline $\begin{array}{l}\text { Post-surgical preventive therapy of } \\
\text { hypocalcemiaף }\end{array}$ & 88 & NA & NA \\
\hline Total & 2373 & 210 & 28 \\
\hline \multicolumn{4}{|l|}{ Re operation } \\
\hline Outpatient visits $\dagger$ & $69(3)$ & $46(2)$ & $20(1)$ \\
\hline $\begin{array}{l}\text { Biological, hormonal measurements } \\
\text { and localization studies }\end{array}$ & 1982 & 164 & 8 \\
\hline Surgery§ & 2100 & NA & NA \\
\hline $\begin{array}{l}\text { Post-surgical preventive therapy of } \\
\text { hypocalcemian }\end{array}$ & 88 & NA & NA \\
\hline \multirow{2}{*}{\multicolumn{4}{|c|}{ UNE }} \\
\hline & & & \\
\hline Outpatient visits $\dagger$ & $69(3)$ & $46(2)$ & $20(1)$ \\
\hline $\begin{array}{l}\text { Biological, hormonal measurements } \\
\text { and localization studies } \dagger\end{array}$ & 733 & 164 & 8 \\
\hline Surgery㧊 & 1890 & NA & NA \\
\hline $\begin{array}{l}\text { Post-surgical preventive therapy of } \\
\text { hypocalcemiaq }\end{array}$ & 88 & NA & NA \\
\hline Total & 2780 & 210 & 28 \\
\hline \multicolumn{4}{|l|}{ VAP } \\
\hline Outpatient visits $†$ & $69(3)$ & $46(2)$ & $20(1)$ \\
\hline $\begin{array}{l}\text { Biological, hormonal measurements } \\
\text { and localization studiest† }\end{array}$ & 754 & 164 & 8 \\
\hline Surgery㧊 & 2189 & NA & NA \\
\hline $\begin{array}{l}\text { Post-surgical preventive therapy of } \\
\text { hypocalcemiaף }\end{array}$ & 88 & NA & NA \\
\hline $\begin{array}{l}\text { Total } \\
\text { Exploration by cervicosternotomy }\end{array}$ & 3100 & Exploration by cervicosternotomy & 28 \\
\hline Outpatient visits $\dagger$ & $69(3)$ & $46(2)$ & $20(1)$ \\
\hline $\begin{array}{l}\text { Biological, hormonal measurements } \\
\text { and localization studies }\end{array}$ & 1982 & 164 & 8 \\
\hline Surgery§§ & 3910 & NA & NA \\
\hline $\begin{array}{l}\text { Post-surgical preventive therapy of } \\
\text { hypocalcemia }\end{array}$ & 88 & NA & NA \\
\hline Total & 6049 & 210 & 28 \\
\hline \multicolumn{4}{|l|}{ Medical follow-up } \\
\hline Outpatient visits (specialist visits) & $23(1)$ & $23(1)$ & $46(1)$ \\
\hline Biological measurements, abdominal & & & \\
\hline ultrasounds and dual X-ray absorptiometry 9 & 145 & 8 & 89 \\
\hline $\begin{array}{l}\text { Total } \\
\text { (b) }\end{array}$ & 168 & 31 & 135 \\
\hline Hematoma*** & 328 & NA & NA \\
\hline \multicolumn{4}{|l|}{ Dysphonia } \\
\hline Medical evaluation of a speech problem††† & $46(2)$ & NA & NA \\
\hline Laryngoscopy†t† & $29(1)$ & NA & NA \\
\hline Vocal-cord re-education sessions $\dagger \dagger \dagger$ & $220(20)$ & NA & NA \\
\hline Total & 295 & NA & NA \\
\hline \multicolumn{4}{|l|}{ Hypoparathyroidism } \\
\hline Outpatient specialist visits ††† & NA & $69(3)$ & $46(2)$ \\
\hline Biological measurements & NA & $96(6)$ & $32(2)$ \\
\hline Alfacalcidol & 31 & 344 & 375 \\
\hline Calcium & 9 & 102 & 111 \\
\hline Total & 40 & 611 & 564 \\
\hline
\end{tabular}

All costs are in $€$ for 2002; NA indicates not applicable. The number of visits, examinations or sessions is indicated in parentheses.

† Outpatients visits denote specialist visits for the first year and general practitioner visits for the subsequent years.

$\ddagger$ Denotes the costs in an ambulatory setting of measurements of PTH, vitamin D, calcemia, protidemia, 24-h urinary calcium, creatininemia, complete blood count, prothrombin time, ECG and CAT in the first month; of measurements of calcemia, protidemia, 24-h urinary calcium, 24-h creatininuria and creatininemia 2-fold in subsequent months of the first year and calcemia annually in the subsequent years. 


\section{Sensitivity analyses}

Comparisons between BNES and UNES Varying rates of complication and QOL weights did not significantly change the effectiveness of BNES compared to UNES. BNES became more effective than and dominated (was more effective and less expensive than) UNES when the risk of mortality associated with UNE exceeded $0.88 \%$ (base-case, $0.00 \%$ ) or when the QOL weight for UNE scarring was less than 0.9885 (basecase, 0.9979).

The incremental cost-effectiveness ratio of UNES versus BNES remained inferior to $€ 6000$ until 80 years of age (Fig. 1). UNES became less costly than BNES and dominated BNES when the cost of UNE was less than $€ 1483$ (base-case, €1890; - 22\%).

Comparisons between UNES and VAPS VAPS was the most effective surgical strategy for otherwise healthy women from 40 to 71 years of age (Fig. 1). UNES became the most effective strategy and dominated VAPS over 71 years, when the risk of mortality associated with VAPS exceeded 0.05\% (base-case, 0.0054\%), the risks of transient or permanent dysphonia associated with VAP exceeded 1.30 or $0.60 \%$, respectively (base-case, 0.64 and $0.38 \%$, respectively), the risk of immediate failure (conversion into BNE excluded) or the annual rate of recurrence after VAP exceeded 3.71 or $0.49 \%$, respectively (base-case, 1.40 and $0.34 \%$, respectively). Lowering the risk of immediate failure or the annual rate of recurrence after UNE under 1.91 or $0.19 \%$, respectively (base-case, 3.30 and $0.34 \%$, respectively) also made UNES the most effective strategy. Also, UNES dominated if QOL weights for permanent dysphonia or for VAP scarring were less than 0.7766 and 0.9984 , respectively (base-case, 0.8913 and 0.9988 , respectively) or if QOL weights for UNE scarring exceeded 0.9984 (base-case, 0.9979). VAPS was less expensive than and dominated UNES if the cost of VAP was less than €2068 (base-case, $€ 2189 ;-6 \%$ ). We also studied the effect of varying the discount rate from 0 to $5 \%$. If the discount rate was $0 \%$, UNES dominated VAPS.
Consequences of the selection among preoperative localization studies The most effective strategy was VAPS when VAP and UNE were performed after sestamibi scintigraphy only, on an outpatient basis (Table 5). UNES became the least costly when UNE was performed after ultrasonography only and was even less costly if UNE was performed during day-care hospitalization. The model was insensitive to the selection among preoperative localization studies before reoperation.

Patients not eligible for surgery The follow-up strategies were less effective but less costly than the surgical strategies in a 55-year-old woman not eligible for surgery (Table $4 b$ ).

Every surgical strategy was more effective than these strategies for women between 40 and 80 years of age, but they remained the least costly (Fig. 1). The incremental cost-effectiveness ratio of UNES compared with Follow-up/UNES increased in older women but remained less than €6000/QALY for women at all ages studied. If no decrement in QOL was associated with lifelong monitoring, Follow-up/UNES became more effective than and dominated UNES: the threshold for the QOL weight of medical monitoring between UNES and Follow-up/UNES was 0.9914 (base-case, 0.9047). No other reasonable changes in the values of the variables led to make Follow-up/UNES more effective than UNES. Follow-up/UNES only dominated UNES when the mortality risk associated with UNE exceeded $15.48 \%$ (base-case, $0.00 \%$ ).

Follow-up/UNES was more expensive than UNES if the annual cost of medical follow-up was more than $€ 216$ (base-case, €132).

\section{Discussion}

To identify the best choice for managing patients with sporadic asymptomatic primary hyperparathyroidism in the absence of a randomized clinical trial comparing all the therapeutic strategies currently used, we used a decision-analytic model. We compared, in a cost-effec-

$\S$ Includes professional fees, anesthesia, surgery and an average 4-day hospitalization.

I Includes a 15-day treatment with calcium and alfacalcidol.

**Bological, hormonal measurements and localization studies (sestamibi scintigraphy, ultrasonography, CT, MRI, venous catheterization with PTH measurements) are performed in a day-care setting before surgery; include also biological tests performed before general anesthesia; calcemia, protidemia, 24-h urinary calcium, $24 \mathrm{~h}$-creatininuria and creatininemia are measured in an ambulatory setting twice in the subsequent months of the first year and calcemia annually in the subsequent years.

†† Biological, hormonal measurements and localization studies (sestamibi scintigraphy and ultrasonography) are performed in a day-care setting before surgery; include also biological tests performed before anesthesia; calcemia, protidemia, 24-h urinary calcium, 24-h creatininuria and creatininemia are measured in an ambulatory setting twice in the subsequent months of the first year and calcemia annually in the subsequent years.

拉 Includes professional fees, anesthesia, surgery and an average 2-day hospitalization.

$\S \S$ Includes professional fees, anesthesia, surgery and an average 7-day hospitalization.

I 9 Denotes the costs of measurements in an ambulatory setting of calcemia, 24-h urinary calcium, creatininemia, creatinine clearance, abdominal ultrasonography and dual-energy X-ray bone absorptiometry (three sites) in the first month; of the measurements of calcemia twice in the subsequent months of the first year and of calcemia biannually, 24-h urinary calcium, creatininemia and dual-energy X-ray bone absorptiometry (three sites) annually in the subsequent years.

*** Denotes the cost of an average 2 days in a hospital and of biological tests. The number of visits, examinations or sessions is indicated between parentheses; two numbers between parentheses denote number during the first year and the following years.

$\dagger \dagger+$ Denotes the costs of biological measurements (calcemia, protidemia, 24-h urinary calcium); the number of measurements is indicated in parentheses. 


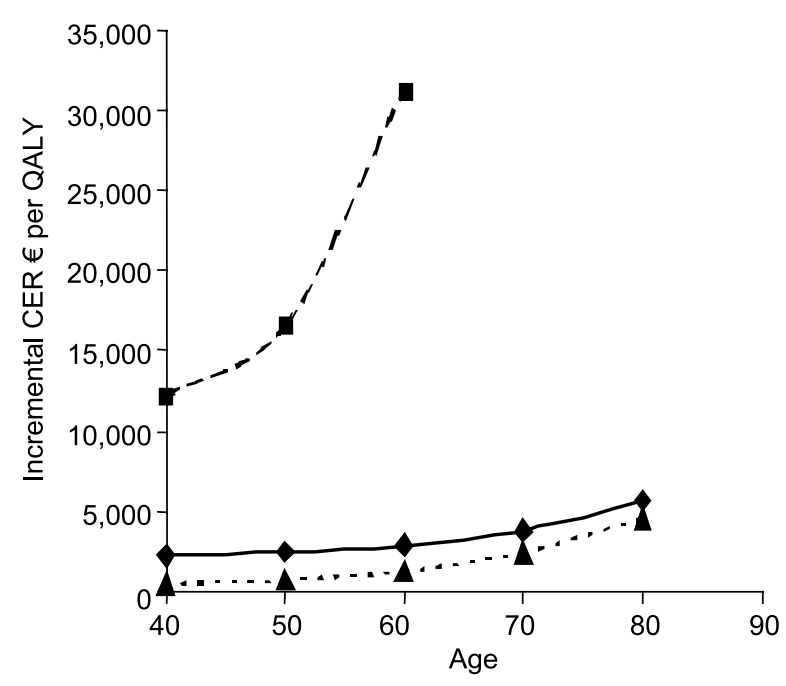

Figure 1 Incremental cost-effectiveness ratios (CERs) of the minimally surgical strategies (VAPS and UNES) versus BNES and UNES versus medical follow-up as a function of patient age. The figure portrays a one-way sensitivity analysis examining the incremental cost-effectiveness ratio of VAPS or UNES compared with BNES and medical follow-up (Follow-up/BNE) as a function of patient age. Incremental cost-effectiveness ratios are shown of: $\checkmark$, UNES versus BNES; $\boldsymbol{\Lambda}$, UNES versus medical follow-up; $\mathbf{\square}$, VAPS versus UNES. The incremental cost-effectiveness ratio of VAPS increases with age. VAPS is no longer the most effective strategy over 69 years. The incremental cost-effectiveness ratio of UNES compared with both BNES and Follow-up/BNE but did not exceed $€ 6000$ until 80 years.

tiveness analysis, the surgical strategies recommended in patients with risk factors for developing complications of hyperparathyroidism and then we compared these strategies with medical monitoring in patients not eligible for surgery $(3,97)$. We found both minimally invasive surgical strategies (UNES and VAPS) to be more effective than the traditional BNES with an acceptable incremental cost-effectiveness ratio (less than $€ 20$ 000/QALY). VAPS was slightly more effective than UNES in a 55-year-old women and UNES became the least expensive surgical strategy if only one preoperative localization study - ultrasonography was performed. Moreover, every surgical strategy was more effective than the medical follow-up strategies except in patients feeling no decrement in QOL. UNES had a very reasonable incremental cost-effectiveness ratio compared with follow-up, even in the elderly.

We estimated the risk of surgical mortality of BNE at $0.21 \%$ between the 0.04 and $0.73 \%$ extreme mortality rates assessed in surgical series (20). The higher surgical risk and the larger decrement in QOL due to the cervicotomy scarring participated in the lower effectiveness of BNES compared with VAPS and UNES. Despite shorter hospital stays and lower reoperation rates, UNES and VAPS had higher average lifetime costs than BNES partly due to the cost of localization studies. However, the incremental cost-effectiveness of UNES makes it a very 'reasonable' choice for patients of all the ages studied $(<€ 6000 / \mathrm{QALY})$. Performing only one localization study instead of two (sestamibi scintigraphy and ultrasonography) before minimally invasive surgery lead to higher efficiency of these strategies. In addition, UNES became the least-costly surgical strategy when ambulatory ultrasonography was performed. In our base-case, both explorations had to localize a single adenoma at the same place for a minimally invasive procedure to be performed, which occurred only in $56 \%$ of cases instead of $77 \%$ and $73 \%$ for sestamibi scintigraphy and ultrasound, respectively. However, if both localization studies were performed at the same time and considered positive if only one of them was positive, the rate of positive localization studies may be higher than that supplied by only one localization study (98). The gain of VAPS compared with UNES was 1.46 days of quality-adjusted life expectancy in our base-case due to a higher QOL weight for scarring and to a lower failure rate of VAP apart from immediate conversion into BNE. Less persistent hyperparathyroidism lead to fewer reoperations and therefore a lower perioperative mortality or morbidity. However, there were a large variety of conditions where VAPS became less effective than UNES. If the failure rate of VAP exceeded $3.71 \%$, VAPS became less effective than

Table 4 Base-case analysis of discounted cost and effectiveness of management strategies for sporadic asymptomatic primary hyperparathyroidism with criteria for (a) surgery and medical follow-up.

\begin{tabular}{|c|c|c|c|c|c|}
\hline Strategy & Cost $(€)$ & QALE (QALY) & $\Delta$ Cost $(€)$ & $\Delta$ Effectiveness (QALY) & $\Delta$ Cost-effectiveness ratio ( $€ / Q A L Y)$ \\
\hline \multicolumn{6}{|l|}{ (a) } \\
\hline BNE & 3537 & 17.0329 & & & \\
\hline UNE & 3766 & 17.1181 & 229 & 0.0852 & 2688 \\
\hline VAP & 3835 & 17.1221 & 69 & 0.0004 & 17250 \\
\hline \multicolumn{6}{|l|}{ (b) } \\
\hline Medical follow-up/BNES & 2538 & 15.7469 & & & \\
\hline Medical follow-up/UNES & 2563 & 15.7543 & 25 & 0.0074 & *Extended dominance \\
\hline BNE & 3537 & 17.0329 & 974 & 1.2786 & 762 \\
\hline UNE & 3766 & 17.1181 & 229 & 0.0852 & 2688 \\
\hline VAP & 3835 & 17.1221 & 69 & 0.0004 & 17250 \\
\hline
\end{tabular}

QALE, quality-adjusted life expectancy (discounted at $3 \%$ per year).

*This is denoted as extended dominance because the incremental cost-effectiveness ratio of medical follow-up/UNES compared with medical followup/BNES is larger than the incremental cost-effectiveness ratio of BNE compared with medical follow-up/BNES. 
Table 5 Analysis of discounted cost and effectiveness of management strategies for sporadic asymptomatic primary hyperparathyroidism with criteria for surgery according to the localization studies performed and to the care setting.

\begin{tabular}{|c|c|c|c|c|c|}
\hline Strategy & Cost $(€)^{*}$ & QALE (QALY) & $\Delta$ Cost $(€)$ & $\begin{array}{l}\Delta \text { Effectiveness } \\
\quad(\text { QALY) }\end{array}$ & $\begin{array}{l}\Delta \text { Cost- effectiveness } \\
\text { ratio }(€ / Q A L Y)\end{array}$ \\
\hline \multicolumn{6}{|c|}{ Ultrasonography only* } \\
\hline UNE & 3458 & 17.1367 & & & \\
\hline VAP & 3517 & 17.1394 & 59 & 0.0027 & 21852 \\
\hline BNE & 3537 & 17.0329 & 20 & & S.D. \\
\hline \multicolumn{6}{|c|}{ Sestamibi scintigraphy only* } \\
\hline BNE & 3537 & 17.0329 & & & \\
\hline UNE & 3707 & 17.1397 & 170 & 0.1068 & 1592 \\
\hline VAP & 3742 & 17.1433 & 35 & 0.0036 & 9722 \\
\hline \multicolumn{6}{|c|}{ Ultrasonography only and UNE (outpatient basis)* } \\
\hline UNE & 3427 & 17.1376 & & & \\
\hline VAP & 3517 & 17.1394 & 90 & 0.0018 & 50000 \\
\hline BNE & 3537 & 17.0329 & 20 & & S.D. \\
\hline \multicolumn{6}{|c|}{ Sestamibi scintigraphy only and UNE (outpatient basis)* } \\
\hline BNE & 3537 & 17.0329 & & & \\
\hline UNE & 3675 & 17.1406 & 138 & 0.1077 & 1281 \\
\hline VAP & 3742 & 17.1433 & 67 & 0.0027 & 24815 \\
\hline \multicolumn{6}{|c|}{ Ultrasonography, scintigraphy and UNE (outpatient basis)* } \\
\hline BNE & 3537 & 17.0329 & & & \\
\hline UNE & 3568 & 17.1188 & 31 & 0.0859 & 361 \\
\hline VAP & 3679 & 17.1221 & 111 & 0.0033 & 33636 \\
\hline
\end{tabular}

QALE, quality-adjusted life expectancy; S.D., standard deviation.

* Indicates changes in selection of localization studies and in the setting of care compared to the base-case. Ultrasonography or sestamibi scintigraphy when performed as the unique procedure is performed on an outpatient basis.

UNES. The first study reporting outcomes of VAP was published in 1998 (99) but the hyperparathyroidism recurrence rate after this procedure is still unknown. Thus we assumed a similar recurrence rate for VAP and UNE $(0.34 \%)$. However, VAPS was no longer the most effective strategy if the annual recurrence rate after VAP increased above $0.49 \%$. We also found that the cost-effectiveness ratio of VAPS versus UNES increased with age until 71 years, and then VAPS became less effective than UNES. Further, VAP is usually performed under general anesthesia. Though none of the VAP series that we analyzed $(80-82,84)$ reported perioperative deaths, the literature (100) reports an extremely low risk of anesthesia-related mortality $(0.0054 \%)$, which we included in our base-case. When this risk was higher $(0.05 \%)$, especially in the elderly with comorbidities, UNES became the preferred strategy over VAPS.

The model was sensitive to variations in the decrement in QOL (changes in QOL weight) for hospitalization, dysphonia and cosmesis. Slight changes in QOL weights for scarring slightly change the efficacy of UNES or VAPS. If QOL weight for UNE scarring increased, UNES dominated VAPS. If QOL weight for VAP scarring increased, VAPS became more cost-effective than in the base-case. It was also sensitive to variations in procedural costs. VAPS became less expensive than UNES if the cost of VAP was $6 \%$ less than the basecase estimate.

Finally, in our study, the strategies of medical monitoring were less effective than surgery. The decrement in QOL found from our population study was reported previously in patients who were minimally hypercalcemic using the SF-36 Health Survey $(17,101,102)$ or a specific tool $(58,103)$. However, some patients may feel no decrement in QOL due to monitoring or non-specific symptoms making the medical follow-up strategies dominant over surgery (the most effective and the least costly). Therefore, patient preferences must be factored into the decision. Surgery became less expensive than follow-up if the annual cost of follow-up exceeded $64 \%$ of the base-case estimate. This could occur if medical therapies were added to this monitoring.

Our study has some limitations. We assumed no increment in mortality due to lifelong medical follow-up. This could have biased the results against the surgical strategy. Controversial results were reported: some studies (104-107) demonstrated a higher risk of mortality in patients with hyperparathyroidism than in the general population, another (18) showed a lower risk of mortality for patients with hyperparathyroidism surgically treated than for others whereas other authors found no increment in mortality of asymptomatic patients (108). Thus further randomized studies involving placement of asymptomatic patients not eligible for surgery into surgical and non-surgical groups, such as the one by Talpos et al. (17), are expected. Because of lack of perspective, we also had to assume that recurrence rate after VAP was similar to that after UNE. Furthermore, practice preferences of surgeons regarding anesthesia or hospitalization length vary. However, our sensitivity analyses examined the consequences of our choices in the base-case. In addition, most of the data analyzed in our literature review were drawn from cohort or 
case-series studies and not from randomized clinical trials. Finally, QOL weights were obtained from a population without the disease instead of a patient population for feasibility reasons.

In most cases, the decision for the management of asymptomatic hyperparathyroidism is driven by a number of individual factors, such as age, general health, individual perception and patient preference. However, the minimally invasive surgical strategies (UNES and VAPS) are the most effective strategies at a reasonable cost except in patients without surgical indication, who prefer medical monitoring. Locally available facilities and expertise should also guide the choice between minimally invasive surgical strategies.

\section{Acknowledgements}

We thank Yvonne Fulla MD, Alexandra Gomola MD, Frederic Sebag MD and Jean François Henry MD for their helpful comments. The study was funded by the Programme National Hospitalier de Recherche Clinique - PHRC AOM 01044.

\section{References}

1 Melton LJ III. The epidemiology of primary hyperparathyroidism in North America. Journal of Bone Mineral Research 200217 (Suppl 2) N12-N17.

2 Adami S, Marcocci C \& Gatti D. Epidemiology of primary hyperparathyroidism in Europe. Journal of Bone Mineral Research 2002 17 (Suppl 2) N18-N23.

3 Bilezikian JP, Potts JT Jr, Fuleihan G, Kleerekoper M, Neer R, Peacock M, Rastad J, Silverberg SJ, Udelsman R \& Wells SA. Summary statement from a workshop on asymptomatic primary hyperparathyroidism: a perspective for the 21 st century. Journal of Clininical Endocrinology \& Metabolism 200287 5353-5361.

4 Silverberg SJ \& Bilezikian JP. Evaluation and management of primary hyperparathyroidism. Journal of Clinical Endocrinology $\mathcal{E}$ Metabolism 199681 2036-2040.

5 Udelsman R. Surgery in primary hyperparathyroidism: the patient without previous neck surgery. Journal of Bone Mineral Research 200217 (Suppl 2) N126-N132.

6 Denham DW \& Norman J. Cost-effectiveness of preoperative sestamibi scan for primary hyperparathyroidism is dependent solely upon the surgeon's choice of operative procedure. Journal of the American College of Surgeons 1998186 293-305.

7 Tsukamoto E, Russell CF, Ferguson WR \& Laird JD. The role of pre-operative thallium-technetium subtraction scintigraphy in the surgical management of patients with solitary parathyroid adenoma. Clinical Radiology $1995 \mathbf{5 0} 677-680$.

8 van Vroonhoven TJ \& van Dalen A. Successful minimally invasive surgery in primary hyperparathyroidism after combined preoperative ultrasound and computed tomography imaging. Journal of Internal Medicine 1998243 581-587.

9 Petti GH Jr, Chonkich GD \& Morgan JW. Unilateral parathyroidectomy: the value of the localizing scan. Journal of Otolaryngology 199322 307-310.

10 Ryan JA Jr \& Lee F. Effectiveness and safety of 100 consecutive parathyroidectomies. American Journal of Surgery 1997173 $441-444$.

11 Vogel LM, Lucas R \& Czako P. Unilateral parathyroid exploration. American Surgery 199864 693-696.

12 Wei JP \& Burke GJ. Analysis of savings in operative time for primary hyperparathyroidism using localization with technetium
$99 \mathrm{~m}$ sestamibi scan. American Journal of Surgery $1995 \mathbf{1 7 0}$ $488-491$.

13 Worsey MJ, Carty SE \& Watson CG. Success of unilateral neck exploration for sporadic primary hyperparathyroidism. Surgery $19931141024-1029$.

14 Norman J, Chheda H \& Farrell C. Minimally invasive parathyroidectomy for primary hyperparathyroidism: decreasing operative time and potential complications while improving cosmetic results. American Surgery $1998 \mathbf{6 4} 391-395$.

15 Udelsman R. Six hundred fifty-six consecutive explorations for primary hyperparathyroidism. Annals of Surgery 2002235 665-670.

16 Miccoli P, Bendinelli C, Berti P, Vignali E, Pinchera A \& Marcocci C. Video-assisted versus conventional parathyroidectomy in primary hyperparathyroidism: a prospective randomized study. Surgery 1999126 1117-1121.

17 Talpos GB, Bone HG III, Kleerekoper M, Phillips ER, Alam M, Honasoge M, Divine GW \& Rao DS. Randomized trial of parathyroidectomy in mild asymptomatic primary hyperparathyroidism: patient description and effects on the SF-36 health survey. Surgery 2000128 1013-1020.

18 Vestergaard P \& Mosekilde L. Cohort study on effects of parathyroid surgery on multiple outcomes in primary hyperparathyroidism. British Medical Journal 2003327 530-534.

19 Vestergaard P \& Mosekilde L. Parathyroid surgery is associated with a decreased risk of hip and upper arm fractures in primary hyperparathyroidism: a controlled cohort study. Journal of Internal Medicine $2004255108-114$.

20 Sosa JA, Powe NR, Levine MA, Udelsman R \& Zeiger MA. Profile of a clinical practice: thresholds for surgery and surgical outcomes for patients with primary hyperparathyroidism: a national survey of endocrine surgeons. Journal of Clinical Endocrinology \& Metabolism $1998 \mathbf{8 3} 2658-2665$.

21 Lowney JK, Weber B, Johnson S \& Doherty GM. Minimal incision parathyroidectomy: cure, cosmesis, and cost. World Journal of Surgery 200024 1442-1445.

22 Mowschenson PM \& Hodin RA. Outpatient thyroid and parathyroid surgery: a prospective study of feasibility, safety, and costs. Surgery 1995118 1051-1053.

23 Doherty GM, Weber B \& Norton JA. Cost of unsuccessful surgery for primary hyperparathyroidism. Surgery $1994116954-957$.

24 Fahy BN, Bold RJ, Beckett L \& Schneider PD. Modern parathyroid surgery: a cost-benefit analysis of localizing strategies. Archives of Surgery 2002137 917-922.

25 Kairaluoma MV, Kellosalo J, Makarainen H, Haukipuro K \& Kairaluoma MI. Cost effectiveness of preoperative ultrasound in primary parathyroid surgery. Annales Chirurgiae et Gynaecologiae $199483279-283$.

26 Goldstein RE, Blevins L, Delbeke D \& Martin WH. Effect of minimally invasive radioguided parathyroidectomy on efficacy, length of stay, and costs in the management of primary hyperparathyroidism. Annals in Surgery $2000231732-742$.

27 Greene AK, Mowschenson P \& Hodin RA. Is sestamibi-guided parathyroidectomy really cost-effective? Surgery $1999 \mathbf{1 2 6}$ 1036-1040.

28 Koslin DB, Adams J, Andersen P, Everts E \& Cohen J. Preoperative evaluation of patients with primary hyperparathyroidism: role of high-resolution ultrasound. Laryngoscope $1997 \quad \mathbf{1 0 7}$ 1249-1253.

29 Roe SM, Brown PW, Pate LM, Summitt JB, Ciraulo DL \& Burns RP. Initial cervical exploration for parathyroidectomy is not benefited by preoperative localization studies. American Surgery $199864503-507$.

30 Sinha CK, Hamaker R, Hamaker RC, Freeman SB, Borrowdale RW \& Huntley TC. Utility of preoperative radionuclide scanning for primary hyperparathyroidism. Laryngoscope $1997107753-758$.

31 Summers GW, Dodge DL \& Kammer H. Accuracy and costeffectiveness of preoperative isotope and ultrasound imaging in 
primary hyperparathyroidism. Otolaryngology and Head Neck Surgery $1989100210-217$.

32 Uden P, Aspelin P, Berglund J, Lilja B, Nyman U, Olsson LE \& Zederfeldt B. Preoperative localization in unilateral parathyroid surgery. A cost- benefit study on ultrasound, computed tomography and scintigraphy. Acta Chirurgica Scandinavia 1990156 $29-35$.

33 Wei JP \& Burke GJ. Cost utility of routine imaging with Tc-99 msestamibi in primary hyperparathyroidism before initial surgery. American Surgery 199763 1097-1100.

34 Weinstein MC, Siegel JE, Gold MR, Kamlet MS \& Russell LB. Recommendations of the Panel on Cost-effectiveness in Health and Medicine. Journal of the American Medical Association $1996 \mathbf{2 7 6}$ $1253-1258$.

35 Neumann PJ, Stone PW, Chapman RH, Sandberg EA \& Bell CM. The quality of reporting in published cost-utility analyses, 1976-1997. Annals of Internal Medicine 2000132 964-972.

36 Drummond MF \& Jefferson TO. Guidelines for authors and peer reviewers of economic submissions to the BMJ. The BMJ Economic Evaluation Working Party. British Medical Journal 1996 $313275-283$.

37 Bilezikian JP \& Potts JT Jr. Asymptomatic primary hyperparathyroidism: new issues and new questions-bridging the past with the future. Journal of Bone Mineral Research $2002 \mathbf{1 7}$ (Suppl 2) N57-N67.

38 Newcombe RG. Two-sided confidence intervals for the single proportion: comparison of seven methods. Statistics in Medicine $199817857-872$.

39 Haff RC, Black WC \& Ballinger WF. Primary hyperparathyroidism: changing clinical, surgical and pathologic aspects. Annals of Surgery $197017185-92$.

40 Irvin GL III, Cohen MS, Moebus R \& Mintz DH. Primary hyperparathyroidism. Current diagnosis, treatment, and results. Archives in Surgery $1972 \mathbf{1 0 5} 738-740$.

41 Kelly TR \& Klein RL. Primary hyperparathyroidism at a community hospital. Amercian Journal of Surgery 1972123 573-576.

42 McGarity WC, Mathews WH, Fulenwider JT, Isaacs JW \& Miller DA. The surgical management of primary hyperparathyroidism: a personal series. Annals of Surgery 1981193 794-804.

43 Anderberg B, Gillquist J, Larsson L \& Lundstrom B. Complications to subtotal parathyroidectomy. Acta Chirurgica Scandinavia 1981 147 109-113.

44 Russell CF \& Edis AJ. Surgery for primary hyperparathyroidism: experience with 500 consecutive cases and evaluation of the role of surgery in the asymptomatic patient. British Journal of Surgery $198269244-247$.

45 Kaplan EL, Bartlett S, Sugimoto J \& Fredland A. Relation of postoperative hypocalcemia to operative techniques: deleterious effect of excessive use of parathyroid biopsy. Surgery 198292 827-834.

46 Saubier EC, Faysse E \& Gouillat C. Surgical treatment of primary hyperparathyroidism. Evaluation of 263 cases [in French]. Journal de chirurgie $1983 \mathbf{1 2 0} 693-699$.

47 Farnebo LO, Trigonis C, Forsgren L, Granberg PO \& Hamberger B. Surgery for primary hyperparathyroidism. Experience with 400 patients during 10 years (1972-1981). Acta Chirurgica Scandinavia Suppl $1984 \mathbf{5 2 0} 11-16$.

48 Blacker JE, Hoover LA, Zuckerbraun L \& Brickman AS. A systematic approach to parathyroid surgery. Clinical Otolaryngology $198611435-441$.

49 Kristoffersson A, Dahlgren K, Granstrand B \& Jarhult J. Primary hyperparathyroidism in Northern Sweden. Surgical Gynecology $\mathcal{E}$ Obstetics 1987164 119-123.

50 Melliere D, Kassab M, Becquemin JP \& Etienne G. Diagnosis and localization of primary hyperparathyroidism [in French]. Presse Medicale $1987161961-1968$.

51 Kraimps JL, Deleplanque G, Carretier M \& Barbier J. Long-term results of surgery of primary hyperparathyroidism [in French]. Journal de chirurgie 1989126 517-520.
52 Lafferty FW \& Hubay CA. Primary hyperparathyroidism. A review of the long-term surgical and nonsurgical morbidities as a basis for a rational approach to treatment. Archives in Internal Medicine $1989149789-796$.

53 Lucas RJ, Welsh RJ \& Glover JL. Unilateral neck exploration for primary hyperparathyroidism. Archives in Surgery 1990125 982-984.

54 Hasselgren PO \& Fidler JP. Further evidence against the routine use of parathyroid ultrasonography prior to initial neck exploration for hyperparathyroidism. American Journal of Surgery 1992 $164337-340$.

55 Bonjer HJ, Bruining HA, Birkenhager JC, Nishiyama RH, Jones MA \& Bagwell CB. Single and multigland disease in primary hyperparathyroidism: clinical follow-up, histopathology, and flow cytometric DNA analysis. World Journal of Surgery $199216737-743$.

56 Nottingham JM, Brown JJ, Bynoe RP, Bell RM \& Haynes JL. Bilateral neck exploration for primary hyperparathyroidism. American Surgeon 199359 115-119.

57 Arkles LB, Jones T, Hicks RJ, De Luise MA \& Chou ST. Impact of complementary parathyroid scintigraphy and ultrasonography on the surgical management of hyperparathyroidism. Surgery $1996120845-851$.

58 Pasieka JL \& Parsons LL. Prospective surgical outcome study of relief of symptoms following surgery in patients with primary hyperparathyroidism. World Journal of Surgery 199822 513-518.

59 Coston SD \& Pelton JJ. Success of cervical exploration for patients with asymptomatic primary hyperparathyroidism. American Journal of Surgery 1999177 69-74.

60 Sprouse LR, Roe SM, Kaufman HJ \& Williams N. Minimally invasive parathyroidectomy without intraoperative localization. American Surgeon 200167 1022-1029.

61 Russell CF, Laird JD \& Ferguson WR. Scan-directed unilateral cervical exploration for parathyroid adenoma: a legitimate approach? World Journal of Surgery 199014 406-409.

62 Chapuis Y, Richard B, Fulla Y \& Bonnichon P. Surgery for primary hyperparathyroidism: an alternative to traditional surgery. Lyon Surgery 199692 375-380.

63 Carty SE, Worsey J, Virji MA, Brown ML \& Watson CG. Concise parathyroidectomy: the impact of preoperative SPECT $99 \mathrm{mTc}$ sestamibi scanning and intraoperative quick parathormone assay. Surgery $19971221107-1114$.

64 Chen H, Sokoll LJ \& Udelsman R. Outpatient minimally invasive parathyroidectomy: a combination of sestamibi-SPECT localization, cervical block anesthesia, and intraoperative parathyroid hormone assay. Surgery 1999126 1016-1021.

65 Moore FD Jr, Mannting F \& Tanasijevic M. Intrinsic limitations to unilateral parathyroid exploration. Annals of Surgery 1999230 $382-388$.

66 Martin RC, Greenwell D \& Flynn MB. Initial neck exploration for untreated hyperparathyroidism. American Surgeon $2000 \mathbf{6 6}$ 269-272.

67 Smit PC, Rinkes IH, van Dalen A \& van Vroonhoven TJ. Direct, minimally invasive adenomectomy for primary hyperparathyroidism: an alternative to conventional neck exploration? Annals of Surgery 2000231 559-565.

68 Kauffmann P, Le Bouedec G, Ptak Y, Vennat JC \& Dauplat J. Parathyroidectomy by elective route with perioperative measurement of parathyroid hormone. Report of 80 cases [in French]. Annals de Chirurgie 2000125 149-154.

69 Mandell DL, Genden EM, Mechanick JI, Bergman DA, Diamond EJ \& Urken ML. The influence of intraoperative parathyroid hormone monitoring on the surgical management of hyperparathyroidism. Archives of Otolaryngology-Head \& Neck Surgery $2001127821-827$.

70 Monchik JM, Barellini L, Langer P \& Kahya A. Minimally invasive parathyroid surgery in 103 patients with local/regional anesthesia, without exclusion criteria. Surgery $2002 \mathbf{1 3 1}$ $502-508$. 
71 Akerstrom G, Rudberg C, Grimelius L, Johansson H, Lundstrom B \& Rastad J. Causes of failed primary exploration and technical aspects of re- operation in primary hyperparathyroidism. World Journal of Surgery $199216562-568$.

72 Billings PJ \& Milroy EJ. Reoperative parathyroid surgery. British Journal of Surgery $1983 \mathbf{7 0} 542-546$.

73 Irvin GL III, Molinari AS, Figueroa C \& Carneiro DM. Improved success rate in reoperative parathyroidectomy with intraoperative PTH assay. Annals of Surgery 1999229 874-878.

74 Shen W, Duren M, Morita E, Higgins C, Duh QY, Siperstein AE \& Clark OH. Reoperation for persistent or recurrent primary hyperparathyroidism. Archives in Surgery 1996131 $861-867$.

75 Weber CJ, Sewell CW \& McGarity WC. Persistent and recurrent sporadic primary hyperparathyroidism: histopathology, complications, and results of reoperation. Surgery $1994 \mathbf{1 1 6}$ 991-998.

76 Granberg PO, Johansson G, Lindvall N, Ohman U, Wajngot A, Werner S \& Willems JS. Reoperation for primary hyperparathyroidism. American Journal of Surgery 1982143 296-300.

77 Norton JA, Schneider PD \& Brennan MF. Median sternotomy in reoperations for primary hyperparathyroidism. World Journal of Surgery $19859807-813$.

78 Russell CF, Edis AJ, Scholz DA, Sheedy PF \& van Heerden JA. Mediastinal parathyroid tumors: experience with 38 tumors requiring mediastinotomy for removal. Annals of Surgery 1981 $193805-809$

79 Dubost CI \& Bouteloup PY. Mediastinal exploration by sternotomy in surgery of hyperparathyroidism 36 cases [in French]. Journal de chirurgie 1988125 631-637.

80 Cougard P, Goudet P, Bilosi M \& Peschaud F. Videoendoscopic approach for parathyroid adenomas: results of a prospective study of 100 patients [in French]. Annals de Chirurgie 2001 $126314-319$.

81 Henry JF, Sebag F, Maweja S, Hubbard J, Misso C, Da Costa V \& Tardivet L. Video-assisted parathyroidectomy in the management of patients with primary hyperparathyroidism [in French]. Annals de Chirurgie $2003128379-384$.

82 Berti P, Materazzi G, Picone A \& Miccoli P. Limits and drawbacks of video-assisted parathyroidectomy. British Journal of Surgery $200390743-747$.

83 Eigelberger MS \& Clark OH. Surgical approaches to primary hyperparathyroidism. Endocrinology \& Metabolism Clinics of North America 200029 479-502.

84 Lorenz K, Miccoli P, Monchik JM, Duren M \& Dralle H. Minimally invasive video-assisted parathyroidectomy: multiinstitutional study. World Journal of Surgery 200125 704-707.

85 Scholz DA \& Purnell DC. Asymptomatic primary hyperparathyroidism. 10-year prospective study. Mayo Clinical Procedures 1981 $56473-478$.

86 Silverberg SJ, Shane E, Jacobs TP, Siris E \& Bilezikian JP. A 10year prospective study of primary hyperparathyroidism with or without parathyroid surgery. New England Journal of Medicine 1999341 1249-1255.

87 NIH Conference, Diagnosis and management of asymptomatic primary hyperparathyroidism: consensus development conference statement. Annals of Internal Medicine 1991114 593-597.

88 Consensus Development Conference, NIH. Consensus development conference statement. Journal of Bone Mineral Research 19916 (Suppl 2) S9-S13.

89 al Zahrani A \& Levine MA. Primary hyperparathyroidism. Lancet $19973491233-1238$

90 Marx SJ. Hyperparathyroid hypoparathyroid disorders. New England Journal of Medicine 2000343 1863-1875.

91 Lau J, Kassirer JP \& Pauker SG. Decision Maker 3.0. Improved decision analysis by personal computer. Medical Decision Making 19833 39-43.

92 Pauker SG \& Kassirer JP. Clinical decision analysis by personal computer. Archives in Internal Medicine 1981141 1831-1837.
93 Pauker SG \& Kassirer JP. Decision analysis. New England Journal of Medicine 1987316 250-258.

94 Beck JR \& Pauker SG. The Markov process in medical prognosis. Medical Decision Making 19833 419-458.

95 Drummond M, Stoddart G \& Torrance G. Cost-utility analysis. In Methods for Economic Evalution of Health Care Programmes, pp 112-148. Eds M Drummond, G Stoddart \& GW Torrance. Oxford: Oxford University Press, 1987.

96 Weinstein MC \& Stason WB. Foundations of cost-effectiveness analysis for health and medical practices. New England Journal of Medicine 1977296 716-721.

97 Consensus Development Conference, NIH. Proceedings of the NIH Consensus Development Conference on diagnosis and management of asymptomatic primary hyperparathyroidism. Bethesda, Maryland, October 29-31, 1990. Journal of Bone Mineral Research 19916 (Suppl 2) S1-S166.

98 Chapuis Y, Fulla Y, Bonnichon P, Tarla E, Abboud B, Pitre J \& Richard B. Values of ultrasonography, sestamibi scintigraphy, and intraoperative measurement of 1-84 PTH for unilateral neck exploration of primary hyperparathyroidism. World Journal of Surgery $1996 \mathbf{2 0} 835-839$.

99 Miccoli P, Bendinelli C, Vignali E, Mazzeo S, Cecchini GM, Pinchera A \& Marcocci C. Endoscopic parathyroidectomy: report of an initial experience. Surgery $1998 \mathbf{1 2 4}$ 1077-1079.

100 Lienhart A, Auroy Y, Péquignot F, Benhamou D \& Jougla E. First results of the study 'Mortality'. French Society of Anaesthesia and intensive care. 45th National congress of anaesthesia and intensive care, pp 203-218. Paris: Actualization Conferences, Elsevier, 2003.

101 Burney RE, Jones KR, Christy B \& Thompson NW. Health status improvement after surgical correction of primary hyperparathyroidism in patients with high and low preoperative calcium levels. Surgery $1999125608-614$.

102 Quiros RM, Alef MJ, Wilhelm SM, Djuricin G, Loviscek K \& Prinz RA. Health-related quality of life in hyperparathyroidism measurably improves after parathyroidectomy. Surgery 2003 $134675-681$.

103 Pasieka JL, Parsons LL, Demeure MJ, Wilson S, Malycha P, Jones J \& Krzywda B. Patient-based surgical outcome tool demonstrating alleviation of symptoms following parathyroidectomy in patients with primary hyperparathyroidism. World Journal of Surgery $200226942-949$.

104 Lundgren E, Lind L, Palmer M, Jakobsson S, Ljunghall S \& Rastad J. Increased cardiovascular mortality and normalized serum calcium in patients with mild hypercalcemia followed up for 25 years. Surgery $2001130978-985$.

105 Palmer M, Adami HO, Bergstrom R, Akerstrom G \& Ljunghall S. Mortality after surgery for primary hyperparathyroidism: a follow-up of 441 patients operated on from 1956 to 1979. Surgery $1987 \mathbf{1 0 2} 1-7$.

106 Hedback G \& Oden A. Increased risk of death from primary hyperparathyroidism-an update. European Journal of Clinical Investigations $1998 \mathbf{2 8} 271-276$.

107 Walgenbach S, Hommel G \& Junginger T. Outcome after surgery for primary hyperparathyroidism: ten-year prospective follow-up study. World Journal of Surgery 200024 564-569.

108 Wermers RA, Khosla S, Atkinson EJ, Grant CS, Hodgson SF, O'Fallon WM \& Melton LJ III. Survival after the diagnosis of hyperparathyroidism: a population-based study. American Journal of Medicine $1998 \mathbf{1 0 4} 115-122$.

109 Weber CJ, Vansant J, Alazraki N, Christy J, Watts N, Phillips LS, Mansour K, Sewell W \& McGarity WC. Value of technetium $99 \mathrm{~m}$ sestamibi iodine 123 imaging in reoperative parathyroid surgery. Surgery $19931141011-1018$.

110 Bergenfelz A, Tennvall J, Valdermarsson S, Lindblom P \& Tibblin S. Sestamibi versus thallium subtraction scintigraphy in parathyroid localization: a prospective comparative study in patients with predominantly mild primary hyperparathyroidism. Surgery $1997121601-605$. 
111 Borley NR, Collins RE, O’Doherty M \& Coakley A. Technetium$99 \mathrm{~m}$ sestamibi parathyroid localization is accurate enough for scan-directed unilateral neck exploration. British Journal of Surgery $199683989-991$.

112 Casas AT, Burke GJ, Sathyanarayana, Mansberger AR Jr \& Wei JP. Prospective comparison of technetium-99m-sestamibi/iodine123 radionuclide scan versus high-resolution ultrasonography for the preoperative localization of abnormal parathyroid glands in patients with previously unoperated primary hyperparathyroidism. American Journal of Surgery $1993 \mathbf{1 6 6}$ 369-373.

113 Gupta VK, Yeh KA, Burke GJ \& Wei JP. 99 m-Technetium sestamibi localized solitary parathyroid adenoma as an indication for limited unilateral surgical exploration. American Journal of Surgery $1998 \mathbf{1 7 6} 409-412$.

114 Hindie E, Melliere D, Jeanguillaume C, Urena P, deLabriolleVaylet C \& Perlemuter L. Unilateral surgery for primary hyperparathyroidism on the basis of technetium Tc $99 \mathrm{~m}$ sestamibi and iodine 123 subtraction scanning. Archives in Surgery 2000 $1351461-1468$

115 Taillefer R, Boucher Y, Potvin C \& Lambert R. Detection and localization of parathyroid adenomas in patients with hyperparathyroidism using a single radionuclide imaging procedure with technetium-99 m-sestamibi (double-phase study). Journal of Nuclear Medicine $1992331801-1807$.

116 van Dalen A, Smit CP, van Vroonhoven TJ, Burger H \& de Lange EE. Minimally invasive surgery for solitary parathyroid adenomas in patients with primary hyperparathyroidism: role of US with supplemental CT. Radiology $2001220631-639$.

117 Nussbaum SR, Thompson AR, Hutcheson KA, Gaz RD \& Wang CA. Intraoperative measurement of parathyroid hormone in the surgical management of hyperparathyroidism. Surgery $1988 \mathbf{1 0 4} 1121-1127$.

118 Fayet P, Hoeffel C, Fulla Y, Legmann P, Hazebroucq V, Luton JP, Chapuis Y, Richard B \& Bonnin A. Technetium-99 m sestamibi scintigraphy, magnetic resonance imaging and venous blood sampling in persistent and recurrent hyperparathyroidism. British Journal of Radiology 1997 70 459-464.

119 Feingold DL, Alexander HR, Chen CC, Libutti SK, Shawker TH, Simonds WF, Marx SJ, Skarulis MC, Doppman JL, Schrump DS \& Bartlett DL. Ultrasound and sestamibi scan as the only preoperative imaging tests in reoperation for parathyroid adenomas. Surgery $2000 \mathbf{1 2 8} 1103-1109$.
120 Thompson GB, Grant CS, Perrier ND, Harman R, Hodgson SF, Ilstrup D \& van Heerden JA. Reoperative parathyroid surgery in the era of sestamibi scanning and intraoperative parathyroid hormone monitoring. Archives in Surgery 1999134 699-704.

121 Levin KE, Gooding GA, Okerlund M, Higgins CB, Norman D, Newton TH, Dun QY, Arnaud CD, Siperstein AE \& Zeng QH. Localizing studies in patients with persistent or recurrent hyperparathyroidism. Surgery 1987102 917-925.

122 Auffermann W, Gooding GA, Okerlund MD, Clark OH, Thurnher S, Levin KE \& Higgins CB. Diagnosis of recurrent hyperparathyroidism: comparison of MR imaging and other imaging techniques. AJR American Journal of Roentgenology $19881501027-1033$.

123 Brennan MF, Doppman JL, Kurdy AG, Marx SJ, Spiegel AM \& Aurbach GD. Assessment of techniques for preoperative parathyroid gland localization in patients undergoing reoperation for hyperparathyroidism. Surgery 198291 6-11.

124 Granberg PO, Hamberger B, Johansson G, Lindvall N, Luthman M \& Ohman U. Selective venous sampling for localization of hyperfunctioning parathyroid glands. British Journal of Surgery 198673 118-120.

125 Prinz RA, Gamvros OI, Allison DJ, Fletcher DR \& Lynn JA. Reoperations for hyperparathyroidism. Surgical Gynecology \& Obstetics 1981152 760-764.

126 Rodriquez JM, Tezelman S, Siperstein AE, Duh QY, Higgins C, Morita E, Dowd CF \& Clark OH. Localization procedures in patients with persistent or recurrent hyperparathyroidism. Archives in Surgery 1994129 870-875.

127 Sugg SL, Fraker DL, Alexander R, Doppman JL, Miller DL, Chang R, Skarulis MC, Marx SJ, Spiegel AM \& Norton JA. Prospective evaluation of selective venous sampling for parathyroid hormone concentration in patients undergoing reoperations for primary hyperparathyroidism. Surgery $1993 \mathbf{1 1 4}$ 1004-1009.

128 Wang CA. Parathyroid re-exploration. A clinical and pathological study of 112 cases. Annals of Surgery $1977186140-145$.

Received 20 May 2005

Accepted 1 September 2005 